\title{
Does Parenting Style predict Emotional Intelligence?
}

\author{
Mary Rachelle Reyes-Wapano, $\mathrm{PhD}$ \\ Xavier Ateneo, Cagayan De Oro City, Philippines
}

\begin{abstract}
This study examined the relationship between parenting styles and $\mathrm{EI}$ in an adolescent population. The sample of this study consisted of 300 respondents, $166(55 \%)$ were females and $134(45 \%)$ were males. The average age of respondents was19.10 years $(S D=1.956)$. Tools used in this study were Trait Meta Mood Scale -TMMS and Parental Authority Questionnaire - PAQ. Regression analyses were conducted to examine the predictive relationships among variables. Results revealed that parenting styles is a significant predict emotional intelligence among adolescents.. This study demonstrated that parenting styles contribute to EI development. The findings provide insight in the field of $\mathrm{EI}$ antecedents and underscore the potential significance of parents' role in the development EI among adolescents
\end{abstract}

Key words: emotional intelligence, parenting styles

\section{INTRODUCTION}

A mong adolescents, emotional intelligence is found to help reduce stress by decreasing conflict, improving relationships and understanding one's own emotions.

Studies have shown that emotional intelligence has a protective effect against suicidal ideation and attempts (Cha \& Nock, 2009; Abdolahhi \& Talib, 2015); against stress (Mikolajczak, Menil, Luminet, 2007; Davis and Humprey, 2012); and against depression (McDougall, 2006; FernandezBerrocal \& Extremera, 2016). Other studies reveal that emotional intelligence has a facilitative effect on overall health and life satisfaction (Landa, Zafra, Martos, \& AguilarLuzón, 2006; Kong Zhao, \& You, 2012).

In light of the evidence in the literature on the prevalence of anxiety and depression in adolescents, (WHO, 2020) and on the potential of emotional intelligence to act as a protective factor against mental ill-health, this study is an attempt to investigate adolescent emotional intelligence, the factors that influence it, specifically, parenting styles

To date, there is a dearth of EI research that target Filipino adolescents. The few that focused on adolescent sample examined EI's association with academic achievement (Sta. Maria, 2007) and performance (Dinglasan, 2004; Manzano, 2004,). Most EI research in the Philippines that focused on adult respondents examined areas as job satisfaction (Asidao, 2001), job performance (Leano, 2006), leadership (Ferrera, 2009), managerial skills (Galla, 2006), and decision-making styles (Natano, 2001). There is, then, a gap of knowledge on adolescent EI and its predictors.

This study then attempts to examine the role of parenting style to emotional intelligence of adolescents.
In this study, EI is conceptualized within the Mayer, Salovey and Caruso EI model (1999) which defines emotional intelligence as ability to "perceive emotions, to access and generate emotions so as to assist thought, to understand emotions and emotional meanings, and to reflectively regulate emotions to promote both better emotion and thought" (Mayer \& Salovey,1997, p. 5) .

The multilevel investment model of emotional intelligence development (Zeidner, Matthews, \& Roberts, 2009) places the research issues in context that relates to temperament and parenting style as determinants of adolescent emotional intelligence. This model of EI development represents some probable causal influences on EI, such as biological and social-learning factors.

Parenting style is conceptualized in this study as parental attempts to control and socialize their children (Baumrind, 1991). Her study assumes that a certain kind of parenting style, that is authoritative parenting style, is positively related to emotional intelligence of adolescents.

\section{Emotional Intelligence}

Mayer and Salovey (2004) describe emotion as one of three or four sets of mental operations. Motivation, identified as the first set of mental processes, is activated as a response to physical drive such as hunger, thirst or sexual needs, which directs organism to satisfy its survival needs. They further proposed that emotions seemed to evolve among mammalian species to point to actual or perceived changes in the environment and to elicit responses to a changing environment, whereas cognition allows the organism to solve problems and learn from its environment and includes learning, memory, and problem solving, information processing that is conscious and flexible (Mayer \& Salovey, 2004). The term emotional intelligence suggests the converging of emotion and cognition. From within this model, emotional intelligence is defined as: The capacity to reason about emotions, and of emotions to enhance thinking. It includes the abilities to accurately perceive emotions, to access and generate emotions so as to assist thought, to understand emotions and emotional knowledge, and to reflectively regulate emotions so as to promote emotional and intellectual growth (p. 197).

The mental ability model of Mayer and Salovey (2000) conceives of emotional intelligence as similar to other intelligences such as cognitive intelligence to the extent that it meets three empirical requirements. Mayer, Salovey and Caruso EI model (2000) enumerates these criteria: First, 
mental problems have definite correct and incorrect answers assessed by systematic scoring method; second, EI correlates with other measures of mental ability; and third, ability increases with age.

\section{Parenting Syle}

In this study, the construct parenting style is understood from the standpoint of Baumrind's (1991) concept of parenting style. From this perspective, parenting style is described as the manner at which parents control and socialize their children. In this definition two important points are noteworthy: first, that this description only seeks to include normal variations in parenting and thus excludes dysfunctional parenting patterns as in abusive families; and second, that parenting styles centers around the issues of control.

Baumrind (1991) identifies two elements of parenting: responsiveness and demandingness. Parental responsiveness, or parental warmth or supportiveness, relates "the extent to which parents intentionally foster individuality, selfregulation, and self-assertion by being attuned, supportive, and acquiescent to children's special needs and demands" (Baumrind, 1991, p. 62). Parental demandingness or behavioral control relates to "the claims parents make on children to become integrated into the family whole, by their maturity demands, supervision, disciplinary efforts and willingness to confront the child who disobeys" (Baumrind, 1991, pp. 61-62).

\section{Related Literature}

Evidence has consistently shown that parenting style is significantly related to emotional intelligence. For example, authoritative parenting style is significantly associated with better emotional intelligence in children, (Fonte, 2009), and who tended to be more socially skilled (Weiss \& Schwarz, 1996). On the other hand, authoritarian parenting style which involves high demandingness and low responsiveness, is found to be associated with low self-esteem, poor social competence, and increased level of depression (Darling, 2010). Children with indulgent parents, those who are considered to be high in responsiveness and low in demandingness, are found to have better self-esteem, are more socially adept, are less depressed, and perform poorly in school (Baumrind, 1991). In view of the strong influence of parenting style on the emotional characteristics of children, it is logical to assume that they also have an influence on the development of children's emotions.

Other more specific factors of parenting patterns, such as child-adult attachment, parenting practices, and family environment, are hereafter reviewed.

Child-adult attachment. Zeidner, Matthews, and Roberts (2009) posited that the quality of child-adult attachment is a major prerequisite for building emotional competencies, which serves as the foundation for the child's creating a positive working model of self and personal relationships.
Experiences with caregivers provide children with the basic elements with which to build an internal model of self. Children with an internal model of self, those with a strong sense of self-esteem and security, feel secure and use this secure space to explore the world. The absence of a secure relationship led a child to perceive emotions as irrelevant or even threatening. Securely attached children are found to have developed the capacity to respond ethically to others as they themselves had been responded to with empathic care giving (Denham, 2003).

Parenting practices. Martinez-Pons (1999) examined how adolescents perceive their parents' parenting practices and their effect on their emotional intelligence. His findings revealed that children who reported that their parents modelled, supported, and rewarded emotionally intelligent behaviors have higher levels of emotional intelligence. These findings are supported by Martinez-Pons (1998) who revealed that parent- models with methods such as encouraging, giving rewards, and guiding have a substantial effect on emotional intelligence, social activities, and symptoms of depression.

Alegre and Benson (2010) investigated the impact of parenting practices and parenting styles on adolescents' emotional intelligence. He found that the mothers who spend more time interacting with their children, and interact with them with educational activities have more emotionally intelligent children than those with less interaction. His findings also revealed that parenting styles affect EI development: controlling parenting style and disciplinarian style negatively influenced the development of EI of children. In contrast, democratic parenting styles positively predicted higher levels of adaptability. The same study also showed that mothers who behave responsibly and demand responsibility from their children also positively affected the children's ability to understand other people's emotions, to establish positive interpersonal relationships, and to take responsibility in social situations. Silick and Schutte (2006) found similar results which showed that greater perceived parental love was related to higher emotional intelligence in children.

Zahn-Waxler (1979) indicated that parental controls have a nonlinear relation with children's emotional competence. For example, with preschool aged children, moderate degrees of control is linked with high levels of emotional competence, while both low and high degrees of control have been associated with lower emotional competence.

Early parental love is associated with development of higher emotional intelligence. Studies on emotional competencies and attachment orientations suggest that secure attachment is positively related to facilitation, understanding, management of emotions, and to total emotional intelligence (Kafetsios, 2004). Adolescents with higher emotional intelligence reported that their parents show more warmth (Mayer, Caruso, \& Salovey, 1999). O’Neil and Parke (2000) also suggested that parents who are responsive and warm have more socially adjusted children who are popular among their friends. 
Specific parenting practices are believed to have strong effects on children's emotional development. Sanchez-Nunez, Fernandez-Berrocal, Montanes, and Latorre (2004) found that parenting practices influence children's coping strategies (Mesters, 2004); their symptoms of depression (Lempers, Clark-Lempers \& Simons, 1989); optimism (Seligman, 1995); social competence (Kuczyinski \& Kochanska, 1995); and selfcontrol (Baumrind, 1966).

Family environment. Related family studies have shown a relationship between family environment and development of emotional competencies. Nixon (1999) showed that there is a relationship between family experiences and children's ability to understand their negative emotions. Nakao (2000) found that family environment has significant effects on children's personal traits such as social skills, emotional control, aggressiveness, anxiety and cognitive intelligence. These studies emphasize that positive family environment is essential to the child's emotional and social development, and that the child's emotional processes are affected by family environment. Martinez-Pons (1998) examined the effects of parents on emotional intelligence of children with ages between 11 and 15 found that parent models with methods such as encouraging, giving rewards, and guiding have central effects on matters of emotional intelligence, social activities, and symptoms of depression.

Additionally, Martinez-Pons (1999) surveyed adolescent perception of parents influence on their own emotional intelligence and their task orientation, social functioning, and symptoms of depression. Through path analysis, this study revealed a significant effect of parental modeling, facilitation and encouragement on adolescents' emotional intelligence.

Research has consistently revealed that parents and care givers who are high in warmth and positive emotions and low in the expression of disapproval, hostility or other negative affect, tended to have children who are socially skilled and well-adjusted (Eisenberg \& Valiente, 2003).

However, there is a dearth of studies that specifically examines the effect EI and parenting styles on adolescent mental health using path analytic methods. Current path analytic studies focused on parenting practices and psychological variables other than emotional intelligence. For example, Sigward (1995) used path analysis to examine parenting styles and self-esteem; Beyers (1999) examined emotional autonomy and perceived parenting interaction; and Wiggers (2003) explored the socio-emotional adjustment of younger children and parent interactive behaviors.

In the Filipino context, parenting style studies focused on its relationship with children's educational attainment. For example, the study of Hindin (2005) revealed girls in disturbed households are less likely to finish elementary school and completed fewer grades; while boys who reported closeness with their mother had higher education, and those who considered their mothers as authoritative have completed secondary school. This study, thus, suggests that parenting style is essential for understanding adolescent educational attainment among Filipino youth.

Additionally, the cross cultural parenting study of Alampay, Cumsille, Darling, Lanz, Marta and Ranieri (2002) concluded that the consistent association between maternal responsiveness and their effort to be familiar with their children has effects on their adolescent children's adjustment. The authors emphasized the significance and potential universality of these maternal behaviors.

To date, there is a lack of research in the area of parenting style and emotional intelligence. Most studies on parenting and children's emotional development have focused on American samples and there is an apparent lack of research of this nature in Filipino families. This study therefore focused on parenting practices and how it predicts emotional intelligence.

\section{Objective}

This study hypothesizes that parenting practices predict the level of emotional intelligence of adolescents, and sought to address this research question: Does parenting style, as perceived by adolescents, predict emotional intelligence among adolescents?

\section{Significance}

The results that parenting styles predict emotional intelligence, led to important implications to parenting and to the value of developing emotional competence, selfawareness, and self-regulation among adolescent children. The results add to the existing body of knowledge on parenting styles and its relationship to EI among children. Although most parenting and EI research has established their relationship, a gap in knowledge exists--as to how parenting and EI combined--affect adolescent mental health. This research had attempted to fill this knowledge gap.

The results of this study may be used to make parents aware of the value of exercising reasonable control over children, setting clear standards of behavior, expressing approval and appreciation, and encouraging responsibility and freedom when appropriate. These authoritative parenting practices allow children to be self-regulated and self-aware. In turn, these emotional competencies, allow children to be confident, capable, and well adjusted.

\section{RESEARCH DESIGN AND METHODS}

\section{Design}

As a predictive research, this study aimed to examine how perceived parenting styles predict emotional intelligence among adolescents

\section{Sample}

There are 300 respondents in this study, $166(55 \%)$ were females and $134(45 \%)$ were males. The average age of respondents was19.10 years $(S D=1.956)$. 


\section{Data Collection}

Communication was sent to the college deans and teachers of the three schools, requesting approval to conduct a research survey. When request was approved, respondents were gathered in large groups. Respondents were informed about the nature of the study and their participation and were then tested. Respondents were assured of confidentiality of their results, and were informed that their individual results will be made available for them. They were also informed to raise questions they find unclear. Participants completed seven questionnaires in about an hour and 20 minutes. The surveys submitted were reviewed for completion by the researcher when the survey was conducted. Completed survey sheets were inspected to check for missing information. Data gathered were then screened, encoded, analyzed, and interpreted.

\section{Data Analysis}

Descriptive statistics were used to establish the profile of research respondents, the range of scores, means, and standard deviations for all measured items. Regression analysis was performed to test whether perceived parenting style significantly predict level of emotional intelligence among adolescents.

\section{Research Instrument}

\section{Trait Meta-Mood Scale (TMMS)}

Emotional intelligence is defined from the standpoint of the Mayer and Salovey EI model: as the ability to "perceive emotions, to access and generate emotions so as to assist thought, to understand emotions and emotional meanings, and to reflectively regulate emotions to promote both better emotion and thought" (Mayer \& Salovey,1997, p. 5). The trait meta-mood scale was the first assessment measure developed by the authors who first identified the EI construct. The TMMS was designed to measure individual differences in the processes of emotional regulation, which includes emotional awareness that further involves monitoring, evaluation, and management of feelings (Mayer, Salovey, Goldman, Turvey, Palfai, 1995) (Appendix B). The TMMS is based on the early notions of EI put forth by Mayer and Salovey (1990).

The TMMS assessed the extent to which individuals attend to their feelings, the clarity of their experience of these feelings, and their ability to regulate their feelings. The TMMS is found to be useful in identifying core individual differences that describe emotionally intelligent individuals. Early EI studies by Mayer and Gaschke (1988) showed that individuals regularly reflect, monitor, evaluate, and manage their feelings; they termed this process as meta-mood experience. The TMMS is designed to assess "relatively stable individual differences in people's tendency to attend to their moods and emotions, discriminate clearly among them, and regulate them (Salovey, Mayer, Goldman, Turvey, \& Palfai, 1995, p.128). It is designed to measure three EI constructs, namely, attention to emotion, clarity of emotion, and emotion repair. Attention to emotion conveys the extent to which individuals notice and think about their feelings; clarity of emotions refers to the ability to understand one's moods; and emotion repair pertains to the degree to which individuals regulate their moods.

The TMMS is found to be an adequate operationalization of the aspects of emotional intelligence (Salovey et. al, 1995). This measure is able to assess individual differences in people's ability to understand, express, and regulate their feelings as well as their ability of using their feelings adaptively. The scales in the TMMS, namely, attention to feelings, clarity of feelings, and ability to regulate one's emotions are fundamental to emotional intelligence (Salovey, et al., 1995).

Previously reported internal consistencies for each subscale are high attention to emotion, $\alpha=.86$; emotional clarity, $\alpha=$ .87 ; and emotion repair $\alpha=.82$ (Salovey, et al., 1995). Validation studies have demonstrated that these constructs can be sufficiently differentiated from related constructs such as neuroticism and repression. The use of self-report measures to assess emotional intelligence "provides a straightforward and economical means for measuring individual differences in emotional functioning." (Zeider et al., 2009,p. 27).Salovey, et al. (1995) did not specify a clear-cut scoring range for interpreting scores. Total EI scores of the adapted TMMS ranged from low of 25 to high of 125 . Using prorate calculation, scores in the range of 30 to 70 , suggest a need to work on emotions, scores near 71 to 110 , suggest a good enough handle on emotions; and 111 to 150 , suggest excellent emotional skills. For emotional attention subscale: scores near 13 to 31 suggest a need to work on emotional awareness; 32 to 48 , suggest growing emotional awareness; and 49 to 65 is considered excellent emotional attention. For subscale emotional clarity: scores near 11 to 25 suggest some confusion; scores near 26 to 40, suggest growing clarity; and scores near 41 to 55 is excellent emotional clarity. For emotional repair: scores 6 to 14, suggest a need to improve self-regulation; near 15 to 22; suggest attempts at emotional repair; and scores near 23 to 30 suggest excellent emotional repair.

\section{Parental Authority Questionnaire (PAQ)}

Parenting style was defined in this study as parental attempts to control and socialize their children (Baumrind, 1991). Perceived parenting style was measured using Parental Authority Questionnaire (PAQ) (Appendix D). The PAQ was developed to assess Baumrind's (1971) parenting prototypes: permissive, authoritarian, and authoritative. This 30-item measure generates permissive, authoritarian and authoritative scores for the identified primary caregiver and is derived from the child's subjective appraisal of his or her parents' authority.

The PAQ has three subscales: permissive, authoritative, and authoritarian parenting styles. Permissive parenting, which includes items $1,6,10,13,14,17,19,21,24$, and 28 , is characterized by parents' relatively low expectations of children's maturity and self-control, permissive parents are 
nontraditional and lenient, are generally nurturing, and are described as high in responsiveness and low in demandingness (Baumrind, 1991).

The authoritarian subscale includes items 2, 3, 7,9,12, 16, 18, 25,26 , and 29. The authoritarian parent expects his or her children to follow the rules he or she established, is punitive, and does not explain the reasoning of these rules to the children.

Authoritative or flexible parenting style was assessed by items $4,5,8,11,15,20,23,27$, and 30. Authoritative parents are described to be democratic; these parents are responsive to their children and are receptive to questions; they are nurturing and forgiving than punishing (Baumrind, 1991).

Scoring for PAQ involves summing the individual items to compose the subscale scores. The PAQ yields three scores, one for each subscale: permissive, authoritarian, and authoritative. Subscale scores range from 10 to 50 (Buri, 1991). There were no cutoff scores suggested to establish group categories. Local norms were used here to classify scores. For authoritative parenting: scores below 25 suggest weak agreement of authoritative descriptions; scores between 26 to 43 suggest a modest agreement; whereas scores 46 to 50 suggest strong agreement. For permissive subscale: scores below 20 suggest lack of endorsement of permissive parenting descriptions; 21 to 39 , moderate agreement; and scores over 40 , suggests strong agreement to permissive descriptions. For authoritarian subscale: scores below 20 suggest weak agreement to authoritarian parenting descriptions; scores between 26 to 39 suggests moderate agreement; and scores over 40 suggests strong agreement.

The PAQ has been found to be psychometrically sound and valid assessment tool for Baumrind's parental styles of both mothers and fathers and has also been found to appropriate for use for male and female older adolescents (Buri, 1991) with reliability coefficients for mothers' and fathers' range from .77 to .92 whereas validation studies have shown that PAQ adequately reflects parenting style constructs (Buri, 1991).

With sample size of 300, reliability testing was performed for PAQ in this study revealed the PAQ to have acceptable reliability (30 items; $\alpha=.69$. Subscale coefficients are as follows: authoritarian, 10 items, $\alpha=.72$; permissive, 10 items, $\alpha=.60$; and authoritative, 10 items, $\alpha=.76$.

\section{RESULTS}

\section{Description of Emotional Intelligence and Perceived Parenting Styles Scores}

Descriptive statistics were used to establish the profile of research respondents, the range of scores, means, and standard deviations for all measured items. Measures of central tendency were computed to summarize the variables of interest in this study. Table 1 shows the means and standard deviations of scores of emotional intelligence, perceived parenting styles and temperament.
Emotional intelligence. As shown in Table 1, the respondents obtained mean score of $87.52(S D=9.08)$ considered in the average range and suggesting an adequate awareness of emotions, clarity, and self-regulation. For EI subscale emotional attention, respondents reported average score 44.15 $(S D=5.98)$, suggesting a growing emotional awareness. For clarity of feelings, respondents obtained mean score of 24.90 $(S D=3.97)$ considered as average scores, suggesting growing emotional clarity. For emotional repair, respondents obtained mean score of $15.50(S D=2.64)$ in emotional repair, suggesting adequate ability at mood management.

Perceived parenting styles. Also shown in Table 1 are the mean and standard deviation scores of perceived parenting styles. On authoritative parenting style, respondents reported moderate agreement to scale descriptions of authoritative parenting $(M=37.53, S D=6.00)$. This revealed respondents' moderate perception of their primary caregivers' as democratic, responsive, and nurturing.

On permissive parenting style, respondents obtained moderate agreement to permissive parenting descriptions $(M=29.54$, $S D=5.25)$. This revealed respondents' moderate perception of parenting style of their primary caregivers as slightly tending towards being nondirective and undemanding.

On authoritarian parenting style, respondents reported slightly above average

( $M=32.50, S D=6.00)$ which revealed respondents' perception of parenting style of their primary caregivers as slightly leaning towards being demanding and directive.

Most respondents, $265(88 \%)$ reported their mothers to be their primary caregivers, $16(5 \%)$ reported their fathers as their primary caregivers, and $9(6 \%)$ reported other individuals care for them. They identified these individuals who cared for them other than their mother or father as their grandparent, an aunt or uncle, or another relative.

\section{Perceived Parenting Styles and Emotional Intelligence}

Regression analysis was performed to test whether perceived parenting style significantly predict level of emotional intelligence among adolescents.

The results of the regression indicated that two parenting styles explained $8.5 \%$ of the variance in emotional intelligence $\left(R^{2}=.085, F(3,296)=9.169, p<.001\right)$.It was found that permissive parenting style significantly predicted emotional intelligence $(\beta=.-172, \quad p<.05)$ as did authoritative parenting style $(\beta=.302, p<.001)$. Regarding effect size, $8.5 \%$ of the variability of EI was explained by parenting styles. Statistical power, computed post-hoc was adequate at .92 .

\section{DISCUSSION}

\section{EI and Perceived Parenting Styles, Temperament,}

Three hundred respondents were assessed in their levels of emotional intelligence, the perceived parenting styles of their 
primary caregivers, their temperament, and the state of their mental health, in terms of perceived self-efficacy, resilience, anxiety, and depression.

Table 1: Means and Standard Deviation Scores of Emotional Intelligence and Perceived Parenting Styles

\begin{tabular}{|c|c|c|c|c|}
\hline Variable & Subscales & $M$ & $S D$ & Range \\
\hline \multirow[t]{4}{*}{$\begin{array}{c}\text { Emotional } \\
\text { Intelligence }\end{array}$} & & 87.52 & 9.08 & $25-125$ \\
\hline & Attention to Emotions & 44.15 & 5.98 & $13-65$ \\
\hline & Clarity of Emotions & 24.90 & 3.97 & $8-40$ \\
\hline & Repair of Emotions & 15.50 & 2.64 & $12-20$ \\
\hline \multicolumn{5}{|l|}{$\begin{array}{c}\text { Perceived } \\
\text { Parenting } \\
\text { Styles }\end{array}$} \\
\hline & Authoritative & 37.53 & 6.00 & $10-50$ \\
\hline & Permissive & 29.54 & 5.25 & $10-50$ \\
\hline & Authoritarian & 32.50 & 6.00 & $10-50$ \\
\hline
\end{tabular}

In terms of their levels of emotional intelligence, respondents' scores reflect moderate, growing emotional skills as emotional attention, clarity and repair. This is understandable in that, at the stage of late adolescence, adolescents develop complex emotional understanding. They are at a developmental stage where they are able to understand social situations, and how these can potentially generate emotional reactions. They are also able to understand emotional display rules and scripts, and hence are able to manage displays of emotion (Saarni, 1999). With more advanced cognitive skills, they are able to understand someone else's perspective, other than their own (Eccles, 1999).

The respondents were also asked to indicate their primary caregiver in the survey questionnaire. Most of the respondents indicated their mothers as their primary caregivers, who they reported as authoritative in their parenting styles, suggesting a balance of parental demandingness and responsiveness.

In terms of temperament, respondents' scores reflect moderate negative affect (e.g., fear, sadness, discomfort, or frustration); moderate effortful control (e.g., voluntary regulation of actions and attention); moderate extraversion that involve sociability and positive affect; and moderate orienting sensitivity to internal stimuli such as thoughts, images, or moods, and environmental prompts.

In terms of mental health, respondents' scores indicate adequate self-efficacy, and adequate ability to adapt to changing situations, (i.e. resilience-mastery). They have slightly above average level of emotional reactivity, suggesting emotional sensitivity and some difficulty at emotional repair. The respondents' level of depression may be considered mild and, anxiety as moderate.

\section{Perceived Parenting Style and Emotional Intelligence}

This study also examined whether parenting style as perceived by adolescent respondents predict overall emotional intelligence. As hypothesized, the results found perceived parenting style to predict emotional intelligence. The results further reveal that perceived authoritative parenting is found to positively predict EI, whereas perceived permissive parenting is shown to be related to reduced EI.

The result that parenting styles, from the report of this study's sample, are key determinants to the development of emotional intelligence is explained by the multilevel investment EI development model (Zeidner et al., 2006). This model underscores parents and family environment as major forces in emotional socialization: parents who, are themselves emotionally skilled, communicate these skills to their children. It is believed that two processes are essential to emotional development of children: direct teaching about emotions and indirect learning from observation and modeling (Zeidner et al., 2009). The teaching and learning of emotional skills appear to be governed by the principles of learning theory, that is, by rewards and punishments. Parents, by their reinforcing behaviors, strengthen or extinguish emotional expressions or skills. In general, parenting styles are believed to relate to the development of EI among children.

Observation and modeling are also believed to be essential to EI development (Zeidner et al., 2009). Modeling of emotions may be two edged: parents may demonstrate functional, constructive emotional behaviors, or inadvertently, dysfunctional, destructive emotional behaviors. Either way, Zeidner et al. (2009) contend that children acquire emotional skills, much more so when they view the emotional behaviors as their parents' behavioral pattern.

From parents, children learn context-specific emotional behaviors (Zeidner et al., 2009). Parents' emotional behaviors become cues to what emotional expressions are acceptable in certain social or cultural settings. Parents' emotional behaviors, then, can function as emotional display rules for children which dictate what is appropriate emotions to express and which are not.

The results showing authoritative parenting, as reported by this study's sample, to positively predict EI is consistent with the parenting literature reviewed. The authoritative parenting approach, described as child-centered, where communication is clear, open, and respectful, and where parents are warm and exert reasonable control, has been shown to predict emotional competence of children. Denham (1998) identified a set of parenting strategies he named as "rewarding socialization of emotion" which has been considered to affect children's emotional competence. This set of parenting strategies includes encouraging and supporting children to express and deal with their feelings positively.

Grolnick andRyan (1989) point to a combination of parental autonomy, encouragement, and support to be predictive of emotional self-regulation among children.

Evidence also suggests that parents, who at the outset have high emotional intelligence, will also display emotionally 
intelligent parenting. Some studies support this thought: Ozabaci (2006) found a significant relationship between family environment and emotional intelligence; Gottman (1997) contends that parents' level of emotional intelligence is associated to their children's emotional intelligence. He suggests that when parents are able to express and manage their own emotions, children develop emotional competence as well; and Denham (1989) suggests that early attachment to a responsive caregiver, such as mother, allows for the development of empathy and pro-social behaviors.

In addition and in contrast to authoritative parenting, the results of this study found permissive parenting to negatively predict EI. This is in agreement with other findings that revealed that adolescent children of authoritative parents were shown to have better psychological well-being and have better social interactions with their peers than children with permissive or authoritarian parents (Shucksmith, Hendry, \&Glendinning, 1995, as cited in Ammerman, 2000). Other studies revealed authoritative parenting to produce children who are self-regulating, self-confident, and empathetic to the needs of others (Baumrind, 1980, as cited in Lyman \& Hembree-Kiggin, 1994), whereas permissive parenting was found to produce self-centered and immature behavior in children (Kochanska, Kuczynski, Radke-Yarrow, 1989, as cited in as cited in Lyman \& Hembree-Kiggin, 1994).

A local study by De Leon (2009), who surveyed Filipino families on the roles parents play in developing "mabuting asal," or positive social behavior among children, revealed that children tend to follow the advice of the non-coercive, non-threatening parent.

It must also be noted that in this work, parenting styles were not directly sourced from parents, and were reported by research respondents. Future research may assess actual selfreports of parents on their parenting styles and practices.

In sum, the results of this current work confirm the importance of the role of parents, their parenting styles and behaviors, to the development of emotional intelligence in adolesencents. The results also suggest that the parental strategies of authoritative parenting style enhance EI development among children. These results are relevant to parents who are earnest in raising emotionally intelligent children.

\section{Implications and General Recommendations}

The findings of this study are relevant in that they reveal the importance of parenting styles, and the influence of temperament on emotional intelligence, and their combined impact to adolescent mental health.

Some general recommendations are presented as well.

\section{Implications and Recommendations}

This study's results are relevant to parents: Parents, then, can adopt, what Zeidner et al. (2006) called, an "emotioncoaching" parenting. Parents, as "emotion coaches," can use their child's negative emotions as opportunities to teach emotion regulation and problem-solving strategies. As emotion coaches, parents can discuss emotions with their children, providing them the distance and space to understand and interpret their feelings, as well as opportunity to reflect on the causes and consequences of their emotions. In doing so, parents can help their children understand emotional expression, situations, and causes.

\section{RECOMMENDATIONS FOR FUTURE RESEARCH}

The limitations of this current work are presented here as well as some recommendations to address this work's limitations in future research of the same theme.

The first limitation is concerned with this study's reliance on self-report measures which focus on the individual's stated self-beliefs, may not encompass the entire range of emotional competencies, psychological distress, or psychological health.With the use of self-report measures there exists a likelihood of the disparity between respondent perception and actual emotional competencies and experiences. However, the variables of interest of this study are subjective experiences which lend to the difficulty in measuring them objectively. They are considered, too, as perception-based and thus are best assessed by the respondents themselves.

Additionally, the use of the self-report measure of EI has been shown to be useful as people, in general, act in consonance with the expressed beliefs of their emotional intelligence (Bandura, 1997). Self-report approach, then, may still be considered a useful tool to collect data and make predictions based on self-reported data (Petrides \& Furnham, 2003). Nonetheless, future studies should include the use of ability measures of EI, as in the Mayer-Salovey-Caruso Emotional Intelligence Test and this assesses emotional competencies. Currently, this is the sole ability-based measure of EI, and because of its cost, is not easily accessible for studentresearchers.

All the measures used in this study were all Western-based. There may, then, be a need to develop and validate measures, such as measures of EI and temperament, relevant to the Filipino culture. These new measurements would improve the reliability and validity of research results and would be a step forward in Sikolohiyang Pilipino in the understanding of the Filipino emotionality. In this study, parenting styles were not directly sourced from parents, and were reported by research respondents. Future research may assess actual self-reports of parents on their parenting styles and practices.

\section{REFERENCES}

[1] Abdollahi, A., \& Talib, M. A. (2015). Emotional intelligence as a mediator between rumination and suicidal ideation among depressed inpatients: The moderating role of suicidal history. Psychiatry research, 228(3), 591-597

[2] Adolescent mental health. (2020, September 28). Https://Ww.Who.Int/News-Room/FactSheets/Detail/Adolescent-Mental-Health. 
https://www.who.int/news-room/fact-sheets/detail/adolescentmental-health

[3] Alegre, A., \& Benson, M. (2010). Parental behaviors and adolescent adjustment: Mediation via adolescent trait emotional intelligence. Individual Differences Research, 8(2), 83-96. Retrieved from PsycINFO database.

[4] Alegre, A. (2011). Parenting styles and children's emotional intelligence: What do we know? The Family Journal, 19(1), 5662. Retrieved from EBSCOhost.

[5] Asidao, Z. (2001). Emotional intelligence: Its influence on the job performance of managers ofselected educational institutions in the division of City Schools, Manila. Unpublished doctoral dissertation, Technological University of the Philippines, Manila.

[6] Augusto-Landa, J., \& Montes-Berges, B. (2009). Perceived emotional intelligence, health and somatic symptomatology in nursing students. Individual Differences Research, 7(3), 197-211. Retrieved from PsycINFO database.

[7] Baumrind, D. (1991). The influence of parenting style on adolescent competence and substance use. The Journal of Early Adolescence, 11(1), 56-95. doi:10.1177/0272431691111004.

[8] Beyers, W., \& Goossens, L. (1999). Emotional autonomy, psychosocial adjustment and parenting: Interactions, moderating and mediating effects. Journal of Adolescence, 22(6), 753-769. doi:10.1006/jado.1999.0268.

[9] Cha, C., \& Nock, M. (2009). Emotional intelligence is a protective factor for suicidal behavior. Journal of the American Academy of Child \& Adolescent Psychiatry, 48(4), 422-430. doi:10.1097/CHI.0b013e3181984f44.

[10] Darling, N. (1999). Parenting style and its correlates. Clearinghouse on elementary and early childhood education. Champaign IL. ERIC Digest.ED427896.

[11] Darling, N., Cumsille, P., Peña-Alampay, L., \& Coatsworth, D. (2009). Individual and issue-specific differences in parental knowledge and adolescent disclosure in Chile, the Philippines, and the United States. Journal of Research on Adolescence, 19(4), 715-740. doi:10.1111/j.1532-7795.2009.00608

[12] Davis, S. K., \& Humphrey, N. (2012). Emotional intelligence as a moderator of stressor-mental health relations in adolescence: Evidence for specificity. Personality and Individual Differences, 52(1), 100-105

[13] Denham, S. A. (1989). Maternal affect and toddlers' socialemotional competence. American Journal of Orthopsychiatry, 59(3), 368-376. Retrieved from EBSCOhost.

[14] De Leon, P. (2009). Parenting practices that promote positive social behavior among preschool children within the family. Retrieved http://www.ovcrd.upd.edu.ph/researchlines/?p=245

[15] Dinglasan, Q. (2004). Correlation of emotional intelligence to the academic performance of Notre Dame University Elementary Training Department pupils.Unpublished master's thesis, Notre Dame University, Cotabato City.

[16] Eisenberg, N., \& Fabes, R. A. (1995). The relation of young children's vicarious emotional responding to social competence, regulation, and emotionality. Cognition and Emotion, 9(2-3), 203228. doi:10.1080/02699939508409009

[17] Eisenberg, N., \& Morris, A. (2002). Children's emotion-related regulation. In R. V. Kail, R. V. Kail (Eds.), Advances in child development and behavior, Vol. 30 (pp. 189-229). San Diego, CA US: Academic Press. Retrieved from EBSCOhost.

[18] Eisenberg, N., Fabes, R. A., Guthrie, I. K., \& Reiser, M. (2000). Dispositional emotionality and regulation: Their role in predicting quality of social functioning. Journal of Personality and Social Psychology, 78(1), 136-157. doi:10.1037/0022-3514.78.1.136.

[19] Fernández-Berrocal, P., \& Extremera, N. (2016). Ability emotional intelligence, depression, and well-being. Emotion Review, 8(4), 311-315

[20] Fonte, B. (2009). Relationship between parenting style, emotional intelligence and self esteem. Published doctoral dissertation. Washington College, Maryland. Retrieved from http://dspace.nitle.org/handle/10090/7271.
[21] Galla, V. (2006).Emotional intelligence: Its relationship with managerial skills. Unpublished Doctoral dissertation. University of Cordilleras, Baguio City, Phillipines.

[22] Gottman, J., Katz, L., \& Hooven, C. (1997). Meta-emotion: How families communicate emotionally. Hillsdale, NJ England: Lawrence Erlbaum Associates, Inc. Retrieved from EBSCOhost

[23] Grolnick, W., \& Ryan, R. (1989). Parent styles associated with children's self-regulation and competence in school. Journal of Educational Psychology, 81(2), 143-154. doi:10.1037/00220663.81.2.143.

[24] Hindin, M. (2005). Family dynamics, gender differences and educational attainment in Filipino adolescents. Journal of Adolescence, 28(3), doi:10.1016/j.adolescence.2004.12.003.

[25] Johnson, B. M., Shulman, S., \& Collins, W. (1991). Systemic patterns of parenting as reported by adolescents: Developmental differences and implications for psychosocial outcomes. Journal of Adolescent Research, 6(2), 235-252. doi:10.1177/074355489162006.

[26] Kafetsios, K. (2004). Attachment and emotional intelligence abilities across the life course. Personality and Individual Differences, 37(1), 129-145. doi:10.1016/j.paid.2003.08.006

[27] Kong, F., Zhao, J., \& You, X. (2012). Emotional intelligence and life satisfaction in Chinese university students: The mediating role of self-esteem and social support. Personality and individual differences, 53(8), 1039-1043.

[28] Lempers, J., Clark-Lempers, D., \& Simons, R. (1989). Economic hardship, parenting, and distress in adolescence. Child Development, 60(1), 25-39. doi:10.2307/1131068.

[29] Manzano, A. (2004). Relationship between emotional intelligence and academic performance. Unpublished master's thesis. University of San Carlos, Cebu City, Phillippines.

[30] Mantzicopoulos, P. Y., \& Oh-Hwang, Y. (1998). The relationship of psychosocial maturity to parenting quality and intellectual ability for American and Korean adolescents. Contemporary Educational Psychology, 23(2), 195-206. doi:10.1006/ceps.1997.0964

[31] Martinez-Pons, M. (1997). The relation of emotional intelligence with selected areas of personal functioning. Imagination, Cognition and Personality, 17(1), 3-13. doi:10.2190/68VDDFXB-K5AW-PQAY

[32] Martinez-Pons, M. (1998). Parental inducement of emotional intelligence. Imagination, Cognition and Personality, 18(1), 3-23. doi:10.2190/U2LJ-3B8U-M9MG-DMJG.

[33] Mayer, J. (2004). What Are the Advantages of a More Focused Approach to EI? Retrieved from http://www.unh.edu/emotional_intelligence.

[34] Mayer, J. D., \& Gaschke, Y. N. (1988). The experience and metaexperience of mood. Journal of Personality and Social Psychology, 55(1), 102-111. doi:10.1037/0022-3514.55.1.102

[35] Mayer, J., \& Geher, G. (1996). Emotional intelligence and the identification of emotion. Intelligence, 22(2), 89-114. doi:10.1016/S0160-2896(96)90011-2.

[36] Mayer, J., \& Salovey, P. (1995). Emotional intelligence and the construction and regulation of feelings. Applied \& Preventive Psychology, 4(3), 197-208. doi:10.1016/S0962-1849(05)80058-7.

[37] Mayer, J., \& Salovey, P. (1995). Emotional intelligence and the construction and regulation of feelings.Applied \& Preventive Psychology, 4(3), 197-208. doi:10.1016/S0962-1849(05)80058-7

[38] Mayer, J. \& Salovey, P. (1997). Emotional development and emotional intelligence. Cambridge University Press: New York.

[39] Mayer, J. D., \& Ciarrochi, J. (2006). Clarifying concepts related to emotional intelligence: A proposed glossary. In J. Ciarrochi, J. Forgas, \& J. D. Mayer (Eds). Emotional intelligence in everyday life (2nd ed). New York: Psychological Press.

[40] Mayer, J., Salovey, P., \& Caruso, D. (2004). Emotional intelligence: Theory, findings, and implications. Psychological Inquiry, 15(3), 197-215. doi:10.1207/s15327965pli1503_02.

[41] Mayer, J., Caruso, D., \& Salovey, P. (1999). Emotional intelligence meets traditional standards for an 
intelligence. Intelligence, 27(4), 267-298. doi:10.1016/S01602896(99)00016-1.

[42] Mayer, J. D., Perkins, D. M., Caruso, D. R., \& Salovey, P. (2001). Emotional intelligence and giftedness.Roeper Review, 23(3), 131137. doi:10.1080/02783190109554084.

[43] Mayer, J., Salovey, P., \& Caruso, D. (2000). Models of emotional intelligence. In R. Sternberg (Ed.), Handbook of intelligence. Cambridge, UK: Cambridge University Press.

[44] Mayer, J., \& Salovey, P. (1995). Emotional intelligence and the construction and regulation of feelings. Applied \& Preventive Psychology, 4(3), 197-208. doi:10.1016/S0962-1849(05)80058-7

[45] Mayer, J., \& Salovey, P. (1997). What is emotional intelligence? In P. Salovey \& D. J. Sluyter(Eds.), Emotional development and emotional intelligence (pp. 3-31). New York: Basic Books.

[46] Mayer, J., Salovey, P., Caruso, D., \& Sitarenios, G. (2003). Measuring emotional intelligence with MSCEIT V2.0. Emotion, 3, 97-105. DOI: 10.1037/1528-3542.3.1.97

[47] Mikolajczak, M., Petrides, K., \& Hurry, J. (2009, June). Adolescents choosing self-harm as an emotion regulation strategy: The protective role of trait emotional intelligence. British Journal of Clinical Psychology, 48(2), 181-193. Retrieved July 26, 2009, doi:10.1348/014466S08X386027.

[48] Nakao, K., Takaishi, J., Tatsuta, K., Katayama, H., Iwase, M., Yorifuji, K., et al. (2000). The influences of family environment on personality traits. Psychiatry and Clinical Neurosciences, 54(1), 91-95. doi:10.1046/j.1440-1819.2000.00642.

[49] Natano, C. (2001). Emotional intelligence: its relationship to the decision-making styles among the tertiary school administrators in the Cotabato Area. Unpublished doctoral dissertation. Notre Dame University, Cotabato City, Philippines.

[50] O'Neil, R., Parke, R., \& McDowell, D. (2001). Objective and subjective features of children's neighborhoods: Relations to parental regulatory strategies and children's social competence. Journal of Applied Developmental Psychology, 22(2), 135-155. doi:10.1016/S0193-3973(01)00073-9.

[51] Ozabaci, N. (2006). Emotional intelligence and family environment. Sosyal Bilimler Dergisi. Retrieved from http://yordam.manas.kg/ekitap/pdf/Manasdergi/sbd/sbd16/sbd-1612.pdf.

[52] Petrides, K. V., \& Furnham, A. (2000). Gender differences in measured and self-estimated trait emotional intelligence. Sex Roles, 42(5-6), 449-461. doi:10.1023/A:1007006523133.

[53] Petrides, K. V., Furnham, A., \& Mavroveli, S. (2007). Trait emotional intelligence: Moving forward in the field of EI. In G. Matthews, M. Zeidner, R. D. Roberts, G. Matthews, M. Zeidner, R. D. Roberts (Eds.) ,The science of emotional intelligence: Knowns and unknowns (pp. 151-166). New York, NY US: Oxford University Press. Retrieved from EBSCOhost.

[54] Pichayapinyo. P., Pawwattana, A., \& Thongvichaen, S. (2008). Parenting styles, Emotional intelligence,and Intelligence quotients in Thai school-aged children in Tukdang community, Bangkok Metropolis. Journal of Public Health, 38(1). Retrieved from http://thailand.digitaljournals.org/index. php/JPH/article/viewFile/2866/2889

[55] Salem-Pickartz, J., \& Donnelly, J. (2007). The Family as a Source of Strength and Life Skill: The Role of Authoritative Parenting in Building Resilience. In A. Loveless, T. B. Holman, A. Loveless, \& T. B. Holman (Eds.), The family in the new millennium: World voices supporting the 'natural' clan, Vol 1: The place of family in human society (pp. 363-368). Westport, CT US: Praeger Publishers/Greenwood Publishing Group. Retrieved from EBSCOhost.
[56] Sánchez-Núñez, M., Fernández-Berrocal, P., Montañés, J., \& Latorre, J. (2008). Does emotional intelligence depend on gender? The socialization of emotional competencies in men and women and its implications. Electronic Journal of Research in Educational Psychology, 6(2), 455-474. Retrieved from PsycINFO database.

[57] Saarni, C. (1999). The development of emotional competence. New York: Guilford Press.

[58] Salovey, P., Woolery, A., \& Mayer, J. (2002). Emotional intelligence: conceptualization and measurement. In. G.J.O. Fletcher, G. Fletcher, \& M.S. Clark (Eds.), Blackwell handbook in social psychology (pp. 279-307). Oxford, UK.Wiley-Blackwell.

[59] Salovey, P. , \& Mayer, J. D. (1990). Emotional intelligence. Imagination, Cognition, and Personality, 9, 185-211.

[60] Salovey, P., Mayer, J., Goldman, S., Turvey, C., \& Palfai, T. (1995). Emotional attention, clarity, and repair: Exploring emotional intelligence using the Trait Meta-Mood Scale. Emotion, Disclosure, \& Health, 125-154. Washington, DC US: American Psychological Association. doi:10.1037/10182-006

[61] Serrat, O. (2009). Understanding and developing emotional intelligence. Knowledge Solutions. Retrieved from http://www.adb.org/documentsMedicine. 2004; 158:760-765.

[62] Sigward, T. (1995, November). Parenting styles and their relationships with young adult's self-esteem and adjustment: A path analysis. Dissertation Abstracts International, 56, Retrieved from PsycINFO database.

[63] Sta. Maria, L. (2007). Emotional intelligence: Its relationship to academic achievement. Unpublished master's thesis. Adventist University of the Philippines, Silang, Cavite.

[64] Strayhorn, J. M., \& Weidman, C. S. (1988). A parent practices scale, and its relation to parent and child mental health. Journal of the American Academy of Child and Adolescent Psychiatry, 27, 613-618.

[65] Weiss, L., \& Schwarz, J. (1996). The relationship between parenting types and older adolescents' personality, academic achievement, adjustment, and substance use. Child Development, 67(5), 2101-2114. doi:10.2307/1131612.

[66] Wiggers, B. (2003, March). The influence of intervention, parent and child characteristics, and parenting on the socio-emotional competence and behavioral adjustment of children with developmental disabilities: A path analysis. Dissertation Abstracts International, 63, Retrieved from EBSCOhost..

[67] Wolfradt, U., Hempel, S., \& Miles, J. V. (2003). Perceived parenting styles, depersonalisation, anxiety and coping behavior in adolescents. Personality and Individual Differences, 34(3), 521532. doi:10.1016/S0191-8869(02)00092-2.

[68] Zahn-Waxler, C., Radke-Yarrow, M., \& King, R.A. (1979). Child rearing and children's prosocial initiations towards victims of distress. Child Development, 50, 319-330.

[69] Zahn-Waxler, C., Cummings, E., McKnew, D. H., \& RadkeYarrow, M. (1984). Altruism, aggression, and social interactions in young children with a manic-depressive parent. Child Development, 55(1), 112-122. doi:10.2307/1129838.

[70] Zeidner, M., Matthews, G., Roberts, R., \& MacCann, C. (2003). Development of emotional intelligence: Towards a multi-level investment model. Human Development, 46(2-3), 69-96. doi:10.1159/000068580.

[71] Zeidner, M., Matthews, G., \& Roberts, R. (2009). What we know about emotional intelligence: How it affects learning, work, relationships, and our mental health. Cambridge, MIT Press. 